\title{
Techno-economic assessment of community energy solutions to network capacity issues
}

DOI:

10.1109/PTC.2017.7980906

\section{Document Version}

Accepted author manuscript

Link to publication record in Manchester Research Explorer

\section{Citation for published version (APA):}

Good, N., Mancarella, P., \& Lintern, K. (2017). Techno-economic assessment of community energy solutions to network capacity issues. In PowerTech, 2017 IEEE Manchester https://doi.org/10.1109/PTC.2017.7980906

\section{Published in:}

PowerTech, 2017 IEEE Manchester

\section{Citing this paper}

Please note that where the full-text provided on Manchester Research Explorer is the Author Accepted Manuscript or Proof version this may differ from the final Published version. If citing, it is advised that you check and use the publisher's definitive version.

\section{General rights}

Copyright and moral rights for the publications made accessible in the Research Explorer are retained by the authors and/or other copyright owners and it is a condition of accessing publications that users recognise and abide by the legal requirements associated with these rights.

\section{Takedown policy}

If you believe that this document breaches copyright please refer to the University of Manchester's Takedown Procedures [http://man.ac.uk/04Y6Bo] or contact uml.scholarlycommunications@manchester.ac.uk providing relevant details, so we can investigate your claim.

\section{OPEN ACCESS}




\section{Techno-economic assessment of community energy solutions to network capacity issues}

\author{
Nicholas Good \\ School of Electrical and Electronic \\ Engineering, University of \\ Manchester, Manchester, UK \\ nicholas.good@manchester.ac.uk
}

\author{
Pierluigi Mancarella \\ Department of Electrical and \\ Electronic Engineering, University of \\ Melbourne, Victoria, 3010, Australia \\ pierluigi.mancarella@unimelb.edu.au \\ School of Electrical and Electronic \\ Engineering, University of \\ Manchester, Manchester, UK \\ p.mancarella@manchester.ac.uk
}

\author{
Kerry Lintern \\ AusNet Services \\ Melbourne, Australia \\ kerry.lintern@ausnetservices.com.au
}

\begin{abstract}
This paper presents a flexible, multi-energy district/community optimization model which can consider multiple energy service demands (hot water, base electricity, space heating/cooling), thermal and electrical energy storage, and solar photo-voltaic generation. The formulation can model various levels of virtual and physical aggregation and accommodate various different pricing structures (on energy and capacity). The model is used to demonstrate how thermal and electrical storage can alleviate network constraints, and how various commercial arrangements for relieving these constraints are effective under different aggregation options. Peak demand, annual cash flow (by component) and measures of energy independence are presented as assessment metrics.
\end{abstract}

Keywords-Smart districts; energy communities; aggregation; optimization; flexibility; energy independence

\section{NOTATION}

Indices

index of settlement periods, 1 to $N_{i}$ index of grid connection points, 1 to $N_{g}$ index of locations, 1 to $N_{l}$ index of VPPs, 1 to $N_{v}$

B. Maps

$\Phi_{g, l}^{G L} \quad$ map of GCP to location

$\Phi_{v, g}^{V G} \quad$ map of VPP to GCP

C. Parameters

1) Resource

$B_{l}^{\text {min }} / B_{l}^{\text {max }}$

$E_{i, l}^{\text {load }}$

$E_{i, l}^{\text {Solar }}$

battery $\mathrm{min} / \max$ capacity $(\mathrm{kWh})$

non-heating (base) electricity load (kWh)

GCPCap $_{g}$ solar electrical energy (kWh)

$H_{i, l}^{D H W}$

GCP capacity $(\mathrm{kW})^{1}$

$M$

DHW heating load (kWh)

$\operatorname{Met}_{i, l} / \operatorname{Sol}_{i, l}$

arbitrarily large number (-)

$O_{i, l} \quad$ Set-point validity indicator (-)

$P_{l}^{B E S \min } / P_{l}^{B E S \max }$ battery $\mathrm{min} / \mathrm{max}$ charge rate $(\mathrm{kW})$

\begin{tabular}{|c|c|}
\hline $\begin{array}{l}P_{l}^{E B \min } / P_{l}^{E B \max } \\
P_{l}^{H V A C \min } / P_{l}^{H V A C}\end{array}$ & $\begin{array}{l}\mathrm{EB} \min / \max \text { power }(\mathrm{kW}) \\
\max \mathrm{HVAC} \min / \max \text { power }(\mathrm{kW})\end{array}$ \\
\hline$S / W$ & binary cooling/heating season indicator (-) \\
\hline$T_{i, l}^{\text {set }}$ & building set temperature $\left({ }^{\circ} \mathrm{C}\right)$ \\
\hline$X_{l}^{\min } / X_{l}^{\max }$ & $\min / \max$ TES energy content $(\mathrm{kWh})$ \\
\hline$X_{i, l}^{\text {loss }}$ & TES heat loss $(\mathrm{kWh})$ \\
\hline$\alpha$ & discretization of set $A$ \\
\hline$\delta$ & blind exclusion efficiency (-) \\
\hline$\eta_{l}^{E B}$ & electric boiler efficiency (-) \\
\hline$\varphi_{l}$ & battery round-trip efficiency (-) \\
\hline$\rho_{i, l}^{H V A C}$ & HVAC COP (-) \\
\hline 2) Price/Weat & her Profiles and Parameters \\
\hline$\lambda_{i}$ & wholesale electricity price $(\$ / \mathrm{kWh})$ \\
\hline$\chi(g)_{i, g}^{-}$ & GCP electricity import price $(\$ / \mathrm{kWh})$ \\
\hline$\chi \operatorname{cap}(g)_{g}^{-}$ & GCP (active power) capacity price $(\$ / \mathrm{kW})$ \\
\hline $\begin{array}{l}\chi(l)_{l}^{-} \\
\mathcal{H}_{l}^{P V}\end{array}$ & $\begin{array}{l}\text { location electricity import price }(\$ / \mathrm{kWh}) \\
\text { solar PV generation incentive }(\$ / \mathrm{kWh})\end{array}$ \\
\hline 3) Time-band & Length \\
\hline$t$ & length of time step (h) \\
\hline Variabl & \\
\hline$B_{i, l}$ & battery energy level $(\%)$ \\
\hline$C_{i, l}^{H V A C} / H_{i, l}^{H V A C}$ & HVAC cooling/heating $(\mathrm{kWh})$ \\
\hline $\mathrm{D}_{i}^{-} / \mathrm{D}_{i}^{+}$ & day-ahead energy import/export (kWh) \\
\hline$E(g)_{i, g}^{-} / E(g)_{i, g}^{+}$ & GCP electricity import/export (kWh) \\
\hline$E(l)_{i, l}^{-} / E(l)_{i, l}^{+}$ & location electricity import/export (kWh) \\
\hline$P_{i, l}^{B E S+} / P_{i, l}^{B E S-}$ & battery export/import power $(\mathrm{kW})$ \\
\hline$P_{i, l}^{E B}$ & EB electrical power $(\mathrm{kW})$ \\
\hline$E(d)_{i} / E(v)_{v, i}$ & district/VPP energy $(\mathrm{kWh})$ \\
\hline$Q(d)_{i}$ & district reactive power ( $\mathrm{kVAr}$ ) \\
\hline$S(d)_{i}$ & district apparent power (kVA) \\
\hline$T_{i, l}$ & building set temperature $\left({ }^{\circ} \mathrm{C}\right)$ \\
\hline$X_{i, l}$ & energy level of thermal energy store ( $\mathrm{kWh})$ \\
\hline$v_{i, l} / w_{i, l}$ & binary HVAC/battery function indicator (-) \\
\hline$y_{i, l} / z_{i, l}$ & binary location/GCP import/export ind (-) \\
\hline$\pi_{i, l} / \beta_{i, l}$ & degree of ventilation of $M e t_{i, l} / S_{i, l}(-)$ \\
\hline
\end{tabular}

${ }^{1}$ It is a variable in peak day run 


\section{INTRODUCTION}

Reducing unit prices of PV panels, policies to reduce greenhouse gas emissions and rising grid electricity prices are increasing interest in solar photo-voltaic (PV) installation globally. In countries with ample solar resource such installations may soon (dependent particularly on regulatory aspects, network tariffs, and degree of self-consumption) become competitive with grid electricity, even without subsidies [1]. This is particularly true for communities for which grid operation, maintenance and expansion are particularly expensive, such as geographically isolated communities, such as those found in rural Australian locations. Such locations may even want to achieve energy 'independence'. However, this may become true in any context relying on per (energy) unit use-of-system (UoS) charges to recoup grid costs, as reducing utilization of grid electricity increases the per unit charge required to recover the largely fixed grid costs [2].

This increasingly attractive value proposition (for the consumer) will motivate increasing penetration of solar PV, which is likely to cluster geographically [3], resulting in very high penetrations in some locations. On constrained connections this may result in capacity problems as the grid struggles to export surplus produced power, which will be high at times of high PV generation and low local demand. Further, a high penetration of PV may result in network voltage (and also thermal) problems [4].

As for the inverse problem of scarce capacity for import (resulting, for example, from electrification of heating and transport or increasing adoption of air-conditioning for cooling) network issues resulting from PV penetration can be assuaged through development of demand response and energy storage resources [5], [6], which can introduce flexibility to deal with network constraints through either storage (shifting grid consumption in time), substitution (switching provision of an energy service to an alternative device/energy vector) or energy service curtailment (reducing consumption of a final energy service) [7]. In this regard, development of a multienergy view may be particularly useful [8]. A key insight such a view brings is the flexibility available from utilizing storage in an intermediate energy vector, such as hot water in a domestic hot water (DHW) system or hydronic heating system [9], or in the building fabric, considering heating or cooling. This may be especially relevant given the substantial amount of energy storage available in heating systems and building fabric.

Whichever demand side interventions are implemented a sound business case will be required for those investing in those interventions. Although capacity services are likely to be most valuable (compared to energy-based services), given that capacity constraints are only active for very limited periods each year, there is significant scope to employ flexibility cultivated primarily for avoidance of capacity expansion for other services, such as temporal arbitrage in multiple markets, or system reserve provision [10]-[13]. This can include arbitrage to reduce UoS fees given time varying UoS charges [14]. For accurate assessment of such business cases, uncertainty of electricity demand and generation determinants (insolation) should be considered. Further, given diversity in demand, physical aggregation of locations within a district so that they share a common grid connection point (GCP), e.g., in microgrid-type arrangements, should be considered as the "smoother" profile of aggregated demand may result in substantial reduction in UoS charges [14] increase in selfconsumption of local generation.

Addressing the issues described above, and drawing on previous work [9], [13], this paper describes a district or community energy optimization model, considering space heating/cooling, DHW and electricity demand, and generation from solar PV. Case studies are presented to demonstrate how the model can be used to assess the capability of districts with energy storage to ameliorate capacity constraints, and how that flexibility can be further exploited for economic gain given access to varying electricity-related prices (for electricity itself, UoS fees and taxes). Further the impact on energy costs and peak demand of dealing with network constraints through a DNO service and a connection capacity fee, under various aggregation arrangements are considered. Metrics of energy independence are also presented, indicating how viable (individual and community) energy independence might be.

\section{MODEL FORMULATION}

The presented formulation uses a MILP approach to model districts of buildings using heating, ventilation and airconditioning (HVAC) units for space heating and cooling, and an electric boiler (EB) for DHW provision. The formulation also allows modelling of solar PV generation and thermal and electrical energy storage. Following the approach used in [13], [14] the model aggregates location level profiles to GCP and then district/virtual power plant (VPP) levels.

\section{A. Modelling the resource}

\section{1) Heating unit operation limits}

Constraints (1)-(2) detail the limits of the EB and HVAC units for each location within the district. Eq. (3) relates the heating and cooling to the HVAC power, whilst (4)-(5) ensure the HVAC unit does not heat and cool at the same time.

$P_{l}^{E B \min } \leq P_{i, l}^{E B} \leq P_{l}^{E B \max }$

$P_{l}^{H V A C m i n} \leq P_{i, l}^{H V A C} \leq P_{l}^{H V A C m a x}$

$H_{i, l}^{H V A C}+C_{i, l}^{H V A C}=P_{i, l}^{H V A C} \rho_{i, l}^{H V A C} t$

$H_{i, l}^{H V A C} \leq M v_{i, l}$

$C_{i, l}^{H V A C} \leq M\left(1-v_{i, l}\right)$

For all $i=1$ to $N_{i}+1, l=1$ to $N_{l}$

\section{2) Storage operation limits}

The district may include a thermal or battery energy store (TES or BES). Constraints (6)-(7) set the limits on the energy content of the TES and the BES. Constraint (8) defines the range of BES charging and discharging. Constraint (9) ensures the battery does not charge and discharge at the same time.

$X_{l}^{\min } \leq X_{i, l} \leq X_{l}^{\max }$

$B_{l}^{\min } \leq B_{i, l} \leq B_{l}^{\max }$

$P_{l}^{B E S \min } \leq P_{i, l}^{B E S-}, P_{i, l}^{B E S+} \leq P_{l}^{\text {BESmax }}$

$P_{i, l}^{B E S+} \leq M w_{i, l}, P_{i, l}^{B E S-} \leq M\left(1-w_{i, l}\right)$

For all $\mathrm{i}=1$ to $\mathrm{N}_{\mathrm{i}}+1, \mathrm{l}=1$ to $\mathrm{N}_{\mathrm{l}}$ 


\section{3) Building thermal comfort limits}

Equality (10) defines that the building temperature should equal the building set temperature whenever an occupant is active (i.e., at home and awake).

$O_{i, l} T_{i, l}=O_{i, l} T_{i, l}^{\text {set }}$

For all $\mathrm{i}=1$ to $\mathrm{N}_{\mathrm{i}}+1, \mathrm{l}=1$ to $\mathrm{N}_{\mathrm{l}}$

4) Initialization

To ensure that the produced results are not distorted, the value of any energy stored within TES, BES and building, at the initial time-step must be set as equal to the last time-step. This condition is implemented by equation (11).

$X_{1, l}=X_{N_{i}+1, l}, B_{1, l}=B_{N_{i}+1, l}, T_{1, l}=T_{N_{i}+1, l}$

For all $\mathrm{l}=1$ to $\mathrm{N}_{\mathrm{l}}$

5) TES and BES system equations

Equation (12) defines the energy content of the TES as a function of the TES energy content, the heat produced by the $\mathrm{EB}$, the TES losses and the amount of DHW provided in the previous time-step. Similarly for the BES, energy content is a function of BES energy content and BES charging/discharging in the previous time-step, see (13).

$X_{i+1, l}=X_{i, l}+P_{i, l}^{E B} \eta_{l}^{E B} \mathrm{t}-X_{i, l}^{\text {loss }}-H_{i, l}^{D H W}$

$B_{i+1, l}=B_{i, l}+\left(P_{i, l}^{B E S-}-P_{i, l}^{B E S+} / \varphi_{l}\right) t$

For all $\mathrm{i}=1$ to $\mathrm{N}_{\mathrm{i}}, \mathrm{l}=1$ to $\mathrm{N}_{\mathrm{l}}$

6) Building system equation

Equation (14) defines the state of the building. To account for natural occupant cooling behavior (15) allows for metabolic heat gains to be neglected (through opening of windows) during winter periods ${ }^{2}$. Similarly (16) allows a proportion of solar heat gains to be neglected during winter periods (through opening of windows and operation of blinds) and during summer periods ${ }^{3}$ (through operation of blinds). During the summer periods neglected solar gains are limited by the blind exclusion efficiency $(\delta)$.

$T_{i+1, l}=T_{i, l}+\left(H_{i, l}^{H V A C}-C_{i, l}^{H V A C}+\left(1-\pi_{i, l}\right) M e_{i, l}+\right.$ $\left.\left(1-\beta_{i, l}\right) \operatorname{Sol}_{i, l}-\left(T_{i, l}-T_{i}^{\text {out }}\right) t R_{l}^{b^{-1}}\right) C_{l}^{b^{-1}}+X_{i, l}^{\text {loss }}$

$0 \leq \pi_{i, l} \leq W$

$0 \leq \beta_{i, l} \leq W+S \delta$

For all $\mathrm{i}=1$ to $\mathrm{N}_{\mathrm{i}}, \mathrm{l}=1$ to $\mathrm{N}_{\mathrm{l}}$

\section{B. Energy balances}

\section{1) Resource-location energy balance}

To allow location level price components to be applied to consumption, relation (18) sums up EB and base load electricity consumption and solar PV generation to location level import and export variables.

Relations in (17) ensure that a location does not import and export at the same time.

$E(l)_{i, l}^{-} \leq M y_{i, l}, E(l)_{i, l}^{+} \leq M\left(1-y_{s, i, l}\right)$

$E(l)_{i, l}^{-}-E(l)_{i, l}^{+}=\frac{H_{i, l}^{E B} t}{\rho_{i, l}^{E B}}+E_{i, l}^{\text {load }}-E_{i, l}^{\text {solar }}$

$E(l)_{i, l}^{-}, E(l)_{i, l}^{+} \geq 0$

For all $\mathrm{i}=0$ to $\mathrm{N}_{\mathrm{i}}, \mathrm{l}=1$ to $\mathrm{N}_{\mathrm{l}}$

\footnotetext{
${ }^{2} W$ is a binary parameter, set to one during winter periods.

${ }^{3} S$ is a binary parameter, set to one during summer periods.
}

\section{2) Location-GCP energy balance}

To facilitate the modelling of potential microgrid/private wire arrangements, equation (21) sums location-level energy consumption and generation to the GCP level, where use-ofsystem (UoS) charges are applied. Relations in (20) ensure electricity cannot be imported and exported at the same time.

$E(g)_{i, g}^{-} \leq M z_{i, g}, E(g)_{i, g}^{+} \leq M\left(1-z_{i, g}\right)$

$E(g)_{i, g}^{-}-E(g)_{i, g}^{+}=\sum_{l=1}^{N_{l}} \Phi_{g, l}^{G L}\left(E(l)_{i, l}^{-}-E(l)_{i, l}^{+}\right)$

$E(g)_{i, g}^{-}, E(g)_{i, g}^{+} \geq 0$

For all $\mathrm{i}=0$ to $\mathrm{N}_{\mathrm{i}}, \mathrm{g}=1$ to $\mathrm{N}_{\mathrm{g}}$

3) GCP-district energy balance

Equation (23) sums GCP level electricity import and export to the district level, variables which are employed when considering the district power constraints (see (26). Equation (24) sums GCP electricity to the VPP level. This can enable one or many GCP to be mapped to one or many VPP.

$\mathrm{E}(\mathrm{d})_{i}=\sum_{g=1}^{N_{g}}\left(E(g)_{i, g}^{-}-E(g)_{i, g}^{+}\right)$
$\mathrm{E}(\mathrm{v})_{v, i}=\sum_{g=1}^{N_{g}} \Phi_{v, g}^{V G}\left(E(g)_{i, g}^{-}-E(g)_{i, g}^{+}\right)$

For all $\mathrm{i}=1$ to $\mathrm{N}_{\mathrm{i}}, \mathrm{g}=1$ to $\mathrm{N}_{\mathrm{g}}, \mathrm{v}=1$ to $\mathrm{N}_{\mathrm{v}}$

\section{District active and reactive power constraints}

Equation (26) defines the linear approximation of the district real power constraint, with the district reactive power constraints defined as in (25) [11].

$Q(d)_{i}=\sum_{l=1}^{N_{l}} \frac{\gamma E_{i, l}^{\text {load }}}{t}$

$-\frac{\alpha\left(\frac{\mathrm{E}(\mathrm{d})_{i}}{l}\right)+S(d)_{i}{ }^{2}}{\sqrt{S(d)_{i}{ }^{2}-\alpha^{2}}} \leq Q(d)_{i} \leq \frac{\alpha\left(\frac{\mathrm{E}(\mathrm{d})_{i}}{l}\right)+S(d)_{i}{ }^{2}}{\sqrt{S(d)_{i}{ }^{2}-\alpha^{2}}}$

For all $\mathrm{i}=0$ to $\mathrm{N}_{\mathrm{i}}, \mathrm{l}=1$ to $\mathrm{N}_{\mathrm{l}}, \alpha \in \mathrm{A}$

If there is a charge levied on the capacity of the connection an initial model run should be undertaken on the peak day with constraint (27) and $\chi c a p(g)_{g}^{-} G C P c a p_{g}$ included in the objective function, where $\chi \operatorname{cap}(g)_{g}^{-}$is the connection capacity charge. The determined GCPCap $_{g}$ values should then be fed back into the model as parameters

$\mathrm{E}(\mathrm{g})_{g, i} / l \leq$ GCPCap $_{g}$

For all $\mathrm{i}=1$ to $\mathrm{N}_{\mathrm{i}}, \mathrm{g}=1$ to $\mathrm{N}_{\mathrm{g}}$

\section{Objective}

The district objective function is given in (28).

$$
\begin{aligned}
& \operatorname{Min}\left\{\sum_{g=1}^{N_{g}} \chi \operatorname{cap}(g)_{g}^{-} G_{C P \operatorname{cap}_{g}}+\right. \\
& \sum_{i=1}^{N_{i}}\left(\lambda_{i} \sum_{v=1}^{N_{v}} \mathrm{E}(\mathrm{v})_{v, i}+\sum_{g=1}^{N_{g}} \chi(g)_{i, g}^{-} E(g)_{i, g}^{-}+\right. \\
& \left.\left.\sum_{l=1}^{N_{l}}\left(\chi(l)_{l}^{-} E(l)_{i, l}^{-}+\varkappa_{l}^{P V} E_{i, l}^{\text {solar }}\right)\right)\right\}
\end{aligned}
$$

\section{CASE STUDIES}

The model is demonstrated through application in the context of Victoria, Australia for a district of poorly-insulated units in a block of flats. UK data is drawn on where Australian data is not available. Initially, in the base case, districts of 25 dwellings are considered, and the network capacity is set according to the peak demand of the district. Subsequently the district is increased to 50 dwellings, to simulate district growth, 
and adoption of solar PV is considered. Similarly to [14], an estimate of annual revenues is made by running the model for eight days: six days represent typical summer/shoulder/winter weekday/weekends, the seventh a "peak" summer (greatest amount of insolation) day, and the eighth a "peak" winter day (coldest day, without solar insolation). Below, the districts are described in detail, before the studied cases are introduced.

\section{A. District}

Each dwelling, for every modelled day, is assigned a realistic, randomly generated DHW, base (non-heat related) electricity and occupancy profile [15], [16]. All profiles are based on UK parameters. The base electrical load is assumed to have a power factor of 0.92 at all times.

Each flat has an electric boiler for DHW provision and a HVAC unit for space heating and cooling. The electric boiler is sized to satisfy DHW demand at all times, whilst the HVAC unit is sized to provide thermal comfort in heating and cooling design conditions. For heating, drawing on UK parameters, this means a building temperature of $21^{\circ} \mathrm{C}$ given outdoor temperature of $-1^{\circ} \mathrm{C}$. For cooling this means a building temperature of $24^{\circ} \mathrm{C}$ given outdoor temperature of $38^{\circ} \mathrm{C}$. The districts are connected to the wider network through a connection sized according to maximum load following demand (without any PV, considering 25 dwellings). Using this method the district connection limit is set at $113 \mathrm{kVA}$.

\section{B. Prices}

Following [14], energy prices are broken down as in Table 1. The GCP level includes transmission, distribution and jurisdictional use-of-system fees (TUoS, DUoS and JUoS). The premises level includes environmental and social obligations (ESO and the goods and sales tax (GST). This aggregation-level distinction allows studying the effect of commercial and physical aggregation. All components apply to import. For export, districts are paid only for exported electricity, and may possibly receive DUoS credit [17].

Table 1: Electricity price components

\begin{tabular}{llll}
\hline & & \multicolumn{2}{c}{ Applicability } \\
\hline Level & Component & Import & Export \\
Commercial & Wholesale electricity & & \\
GCP & DUoS fees & & \\
& JUoS fees & & \\
\multirow{2}{*}{ Premises } & TUoS fees & ESO & \\
& GST & & \\
\hline
\end{tabular}

In this study typical Victorian electricity components are utilized. Figure 1 shows the import and export price components for peak summer/winter days.

\section{Cases}

As a base case $2.42 \mathrm{~kW}$ of PV panels are added to each flat. This is the maximum that can be accommodated given the network capacity. Then, the presented model is used to demonstrate how two types of flexible devices, as detailed in Table 2, may be used to enable connection of further solar PV resources which otherwise would result in unacceptable violation of connection capacity or PV curtailment. Then, in each test case a total of $3.125 \mathrm{~kW}$ of PV panels are added to each flat. Without flexibility this amount of PV would result in maximum export exceeding district connection capacity by $50 \%$. For case A, the storage was sized to the minimum which would enable the district maximum export to remain below an acceptable level. For case B, the TES was sized at 150 liters, typical in the UK.

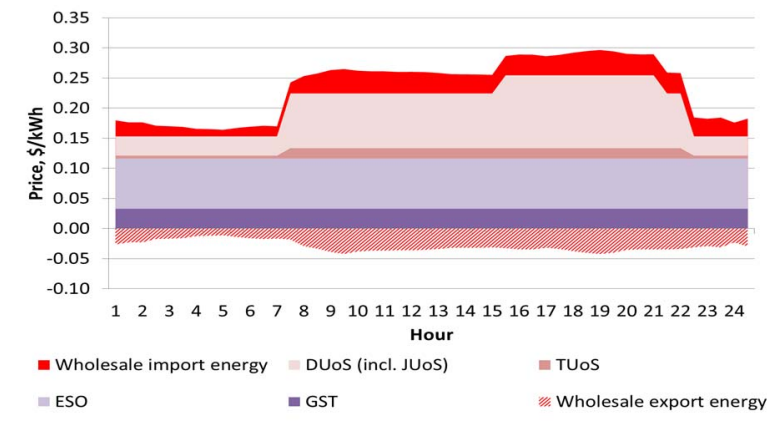

Figure 1: Price components for a peak summer day

Table 2: Flexible device parameters per building

\begin{tabular}{|l|l|l|l|}
\hline Case & Description & Size & $\begin{array}{l}\text { Charge/discharge } \\
\text { power }\end{array}$ \\
\hline A & BES & $4.5 \mathrm{kWh}$ & $2.25 \mathrm{~kW}$ \\
\hline $\mathrm{B}$ & TES & 150 liters & \\
\hline
\end{tabular}

For each of the above technology cases, following the method in [14] three aggregation options are considered. As shown in Table 3 the options vary on whether there is coordination at the building level or district level, so that the district operates as one commercial unit, and on the ownership of the local network (if it is DNO owned, UoS fees are charged on import/export at each building, if district owned, UoS fees are charged on district import/export).

Table 3: Aggregation options

\begin{tabular}{|l|l|l|}
\hline $\begin{array}{l}\text { Aggregation } \\
\text { option }\end{array}$ & Coordination & $\begin{array}{l}\text { Local network } \\
\text { ownership }\end{array}$ \\
\hline 1 & Building & DNO \\
\hline 2 & District & DNO \\
\hline 3 & District & District \\
\hline
\end{tabular}

Then, for each technology case and aggregation option, two commercial arrangements for avoiding distribution network constraints are considered, Table IV. Arrangement $\alpha$ involves the DNO paying district consumers to maintain apparent power below the network limit. Arrangement $\beta$ involves the DNO charging a connection capacity fee (on active power). These fees are determined by increasing the connection fee in increments of $\$ 0.1 / \mathrm{kW}$, for each test day, until either the network limit is satisfied or the peak power can fall no further. The GCP peak power is then set as the limit.

\begin{tabular}{|l|l|} 
Table IV: Commercial options \\
\begin{tabular}{|l|l|}
\hline Commercial option & \\
\hline$\alpha$ & DNO service \\
\hline$\beta$ & Connection capacity fee \\
\hline
\end{tabular}
\end{tabular}

\section{RESULTS}

Flexible device behavior is first presented for combination $\mathrm{A} / 1 / \alpha$ and $\mathrm{B} / 1 / \alpha$. These results demonstrate how imposing a hard limit on network apparent power motivates behavior of flexible devices, when the constraint is active. Behavior on 
peak summer and winter days are studied. Subsequently the district peak demand, cash flows and metrics of 'energy independence' for the districts are presented.

\section{A. Network capacity constraints}

In Figure 2 case A demonstrates usage of the battery in response to connection capacity, importing during times of high PV generation, and exporting the previously imported energy in the evening, to reduce the volume of higher priced imports (see Figure 1). In case B the flexibility engendered by the TES is used to shift EB import away from the high price 16:00-21:00 period, to the late morning, where it can soak up PV generation, and help keep apparent power below network limits. In all cases the district apparent power does violate the nominal connection capacity during periods of peak PV generation. This may be acceptable, as components can operate above their nominal capacities for limited periods.

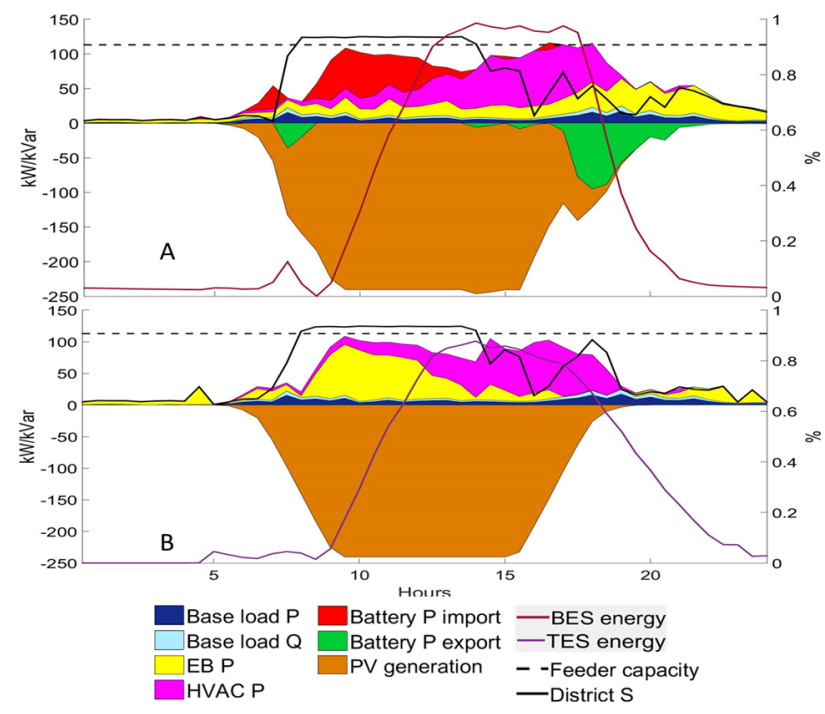

Figure 2: District behavior, by case, peak summer day

\section{B. District metrics}

\section{1) District peak power}

Figure 3 shows the maximum district apparent power by case. As shown, the $\alpha$ cases (in which a hard limit on district apparent power is implemented, see section III.C) are able to limit apparent power to an acceptable level (in excess of the nominal limit, but by a limited amount). For the $\beta$ cases the nominal limit is breached by a large amount when DNO ownership of the local network is considered. This is because, for these aggregation options, limits are on each dwelling, meaning there is no incentive for individual dwellings to act in concert for the benefit of the district. When district ownership of the local network is considered the peak power comes down significantly, as dwellings can exchange power within the district to meet GCP active power limits.

2) Cost

As demonstrated in Figure 2, besides enabling integration of PV generation, the implemented storage can be used to reduce district costs by shifting grid import/export to low/high price periods. By scaling the results of the eight representative days up to a year, and comparing to a base case (see section
III.C), the revenue benefit for various cases can be quantified. This includes, for $\alpha$ arrangements, also a theoretical 'DNO service' revenue. This is the difference in revenue between the given cases and equivalent cases without connection constraint (the opportunity cost for the district of connection constraint removal). This revenue might be paid by the DNO for constraint alleviation. As shown in Figure 3, the most significant revenue change for the district is related to ESO and GST. This is because the storage is implemented on individual premises, allowing premises level consumption, on which ESO and GST are charged, to be minimized. If a centralized/community storage was instead utilized, this benefit would be eliminated. Also significant is the reduction in DUoS and JUoS payments (resulting in a positive change in operational revenue), as the relatively steep and frequent differentiations in price levels provides ample opportunity for arbitrage. This change is slightly reduced for the $\beta$ cases compared to the $\alpha$ cases given the inclusion of the GCP capacity payments in these cases.

Overall the battery cases demonstrate the greatest increase in revenue. This reflects the lesser losses from battery charge/discharge compared to TES thermal losses. Considering aggregation arrangements, arrangement 3 has greater revenue than other arrangements, as diversity within the district can be exploited to avoid UoS fees to a greater extent. Comparing $\alpha$ and $\beta$ cases, the revenue is not much changed. This may seem odd, given the often large differences in peak demand. However, these peak demand scenarios occur very infrequently, so over the year the effect is negligible. This may, however change if a stochastic approach is used, which recognizes that demand and generation profiles, and hence peak power, are uncertain, and action to minimize peak power may be required on many days, not just the peak day.

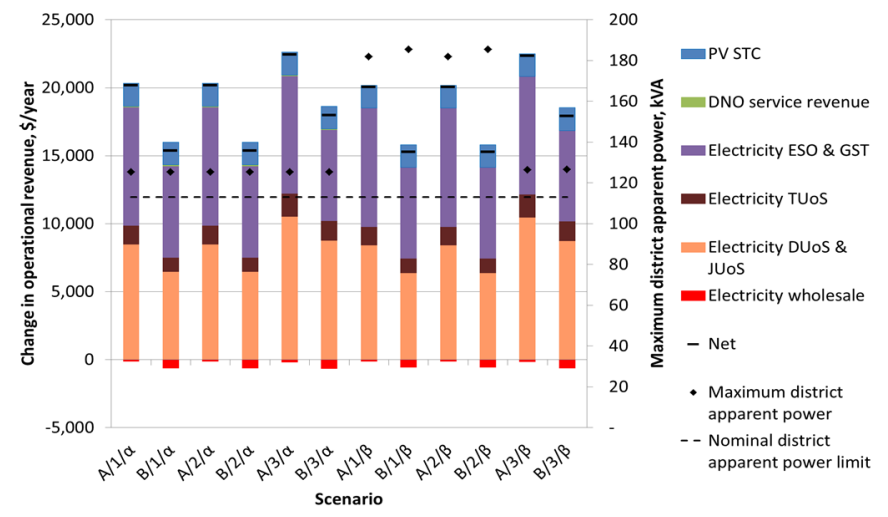

Figure 3: Change in District cash flow, compared to base case, and maximum district apparent power ${ }^{4}$

\section{3) Energy independence}

To measure energy independence (which we define as $100 \%$ self-consumption of generation and $100 \%$ self-service of consumption), at the building and district level, as appropriate by case, several metrics might be of interest. In Figure 4 the locational and district (weighted) average percentages of

\footnotetext{
${ }^{4}$ PV STC $=$ Photo-voltaic small scale technology certificate. These are paid dependent on the $\mathrm{kW}$ size of the installation.
} 
demand self-served by local generation and local generation self-consumed are presented for selected cases ${ }^{5}$. As shown, energy independence is closer to realization if considered at the district level, emphasizing the benefits of aggregation. That more demand is self-served than generation self-consumed indicates that there is scope to add storage to improve these metrics, though they may anyway improve somewhat under an energy independence objective.

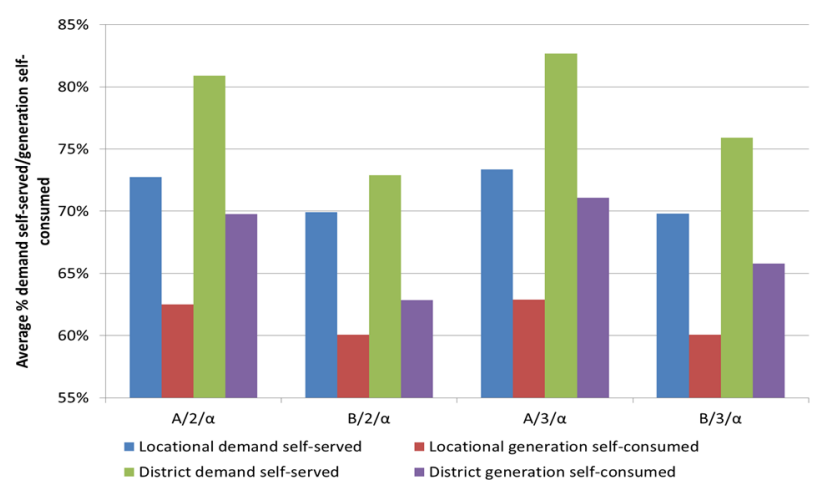

Figure 4: Energy independence metrics, selected cases

\section{CONCLUSION}

This work has presented an optimization formulation to model multi-energy (electricity and heat) districts, including various multi-energy storage devices. The effect of virtual and physical aggregation options (district coordination and local network ownership) have been investigated, as have the effects of methods for limiting district power below network limits.

Case studies have demonstrated how storage, in the form of TES and batteries, may be employed to alleviate distribution network constraints and also minimize costs. Cost savings for the district and (when using a connection capacity fee) reduced peak power of physical aggregation (local network ownership) have been assessed. Also demonstrated was the low cost and the effectiveness of using a 'DNO service' to alleviate network constraints, though possibly significant transaction costs and the difficulty in obtaining a baseline to measure foregone revenue were not considered. Metrics of energy independence, at the location and district level, were also presented indicating that aggregation improves these metrics and brings the district closer to achieving energy independence.

Future work will consider trade-offs between energy independence and cost, to indicate the cost of becoming energy-independent. Consideration of uncertainty should also be included, as this could significantly affect results. A more robust treatment of network limits will also be developed. Finally, new studies will be considered to address ongoing changes, such as smaller roof sizes, reduction in electric hot water systems, changes in load diversity, etc.

\section{ACKNOWLEDGEMENT}

This work was developed with the contribution and within the scope of the UK EPSRC MY-STORE project (EP/N001974/1).

${ }^{5}$ The cases are selected as significant changes in these metrics, for both battery and TES cases, occur when moving from DNO to district ownership.

\section{REFERENCES}

[1] S. Hagerman, P. Jaramillo, and M. G. Morgan, "Is rooftop solar PV at socket parity without subsidies?," Energy Policy, vol. 89, pp. 84-94, 2016.

[2] R. Khalilpour and A. Vassallo, "Leaving the grid: An ambition or a real choice?," Energy Policy, vol. 82, no. 1, pp. 207-221, 2015.

[3] N. Good, K. A. Ellis, and P. Mancarella, "Demand Response and the Smart Grid: Review, Analysis and Classification of Socio-TechnoEconomic Barriers and Enablers," Renew. Sustain. Energy Rev., vol. In Press, 2017.

[4] A. Navarro-Espinosa and L. F. Ochoa, "Probabilistic Impact Assessment of Low Carbon Technologies in LV Distribution Systems," IEEE Trans. Power Syst., pp. 1-12, 2015.

[5] E. A. Martínez-Ceseña, N. Good, and P. Mancarella, "Electrical network capacity support from demand side response: Techno-economic assessment of potential business cases for small commercial and residential end-users," Energy Policy, vol. 82, pp. 222-232, Jul. 2015.

[6] R. Poudineh and T. Jamasb, "Distributed generation, storage, demand response and energy efficiency as alternatives to grid capacity enhancement," Energy Policy, vol. 67, pp. 222-231, Dec. 2014.

[7] B. Daryanian, R. E. Bohn, and R. D. Tabors, "Optimal demand-side response to electricity spot prices for storage-type customers," IEEE Trans. Power Syst., vol. 4, no. 3, pp. 897-903, 1989.

[8] P. Mancarella, "MES (multi-energy systems): An overview of concepts and evaluation models," Energy, vol. 65, pp. 1-17, Nov. 2014.

[9] N. Good, E. Karangelos, A. Navarro-Espinosa, and P. Mancarella, "Optimization under Uncertainty of Thermal Storage-Based Flexible Demand Response with Quantification of Residential Users' Discomfort," IEEE Trans. Smart Grid, vol. 6, no. 5, pp. 2333-2342, 2015.

[10]N. Good, E. A. Martínez-Ceseña, and P. Mancarella, "Business cases," in Energy positive neighborhoods and smart energy districts: methods, tools and experiences from the field, A. Monti, P. Mancarella, K. Kouramas, D. Pesch, and K. Ellis, Eds. Elsevier, 2016.

[11]R. Moreno, R. Moreira, and G. Strbac, “A MILP model for optimising multi-service portfolios of distributed energy storage," Appl. Energy, Sep. 2014.

[12]R. Moreira, R. Moreno, and G. Strbac, "Synergies and Conflicts Among Energy Storage Services,” in EnergyCon 2016, 2016.

[13]N. Good and P. Mancarella, "Modelling and assessment of business cases for smart multi-energy districts," in PSCC, 2016.

[14]N. Good, E. A. Martínez-Ceseña, L. Zhang, and P. Mancarella, "TechnoEconomic and Business Case Assessment of Low Carbon Technologies in Distributed Multi-Energy Systems," Appl. Energy, vol. 167, pp. 158-172, 2016.

[15]I. Richardson, M. Thomson, D. Infield, and C. Clifford, "Domestic electricity use: A high-resolution energy demand model," Energy Build., vol. 42 , no. 10 , pp. $1878-1887$, Oct. 2010.

[16]N. Good, L. Zhang, A. Navarro-Espinosa, and P. Mancarella, "High resolution modelling of multi-energy domestic demand profiles," Appl. Energy, vol. 137, pp. 193-210, Jan. 2015.

[17] AusNet Services, "Electricity Distribution: Annual Tariff Proposal 2016," 2016. 